\title{
A Study on Industry Inosculated Development and Integrated Innovation Based on Modularity Theory
}

\author{
Gang KONG ${ }^{1, a}$, Qian $\mathrm{LI}^{2, \mathrm{~b}}$
}

${ }^{1}$ State Grid Shandong Electric Power Research Institute, No.2000 of Wangyue Road, Jinan, China

${ }^{2}$ State Grid Shandong Electric Power Training Center, No.366 of southern Road, Jinan, China

akonggang10285@126.com, b176102886@qq.com

Keywords: Telecommunication industry, Modularity, Inosculated development, Integrated innovation.

\begin{abstract}
The paper re-constructs modularly Chinese telecommunication industry according to the visible rules (structure, interface, and standard) and invisible rules of Modularity Theory. Based on them, the paper advances the paths of integrated innovation which consider "integrated learning of competition and cooperation" as the main model and the way to upgrade industrial competition advantage which consider " integrated value creation grounded on congregating the excellent submodule resource all over the world" as the leading pattern.
\end{abstract}

\section{Introduction}

In the 4G times under the background of "triple-networks convergence, the restructure of industrial chain of Chinese Telecom highlights the importance of demands of modularity and integrated innovation. Modularity of division of work is changing the existing industry organize, and reinventing microcosmic groundwork and essential structure(Baldwin and Clark, 1997, so as to become the essence of new industrial structure(Masahi ko Aoki, 2002). The essence of integrated innovation is the overlapping convergence, modularity and integrated innovation brings to the new and deeper view of inosculated development of Chinese Telecom in the new economic times, then constitute the important path and fountainhead of promoting industrial competence advantage.

\section{Review}

The ides of modular comes from most early field of engineering(Davidow \& Malone,1992), possesses some kind independent function Subsystem, can make up more complex system by standardizing interface through certain rule and mechanism(Masahi ko Aoki, 2002). Modularization refers to the dynamic conforming process of dividing the complex system into different modular and system communicating by the standing interface based on knowledge and rules(Masahi ko Aoki, 2002). Different from the feature of conventional division of work based on specifies, modularized division work is the division of the work on the net based on knowledge and function, can overcome abuse of heavy set specificity from traditional roles. The difference between it as is shown in the figure 1 .

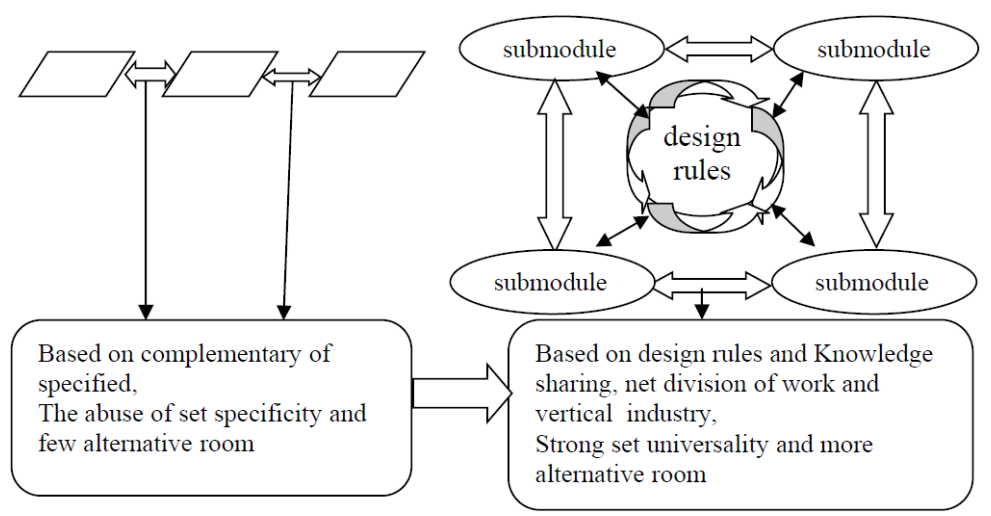

Figure 1 from traditional division to modularized division of work 
Xiaopeng Wang (2004) explained the relation between structure of division and module and evolution paths from the view of dominant factor to resource change. Used research about modular theory at home and abroad mostly focus on the field of physics. In view of background of industry convergence, research the industry innovation of "invisible service" such as Telecom pulling in modular theory can recuperate the shortage. The paper based on industry amalgamation of Telecom with the theory of modular and integrated innovation. Actually, modular idea constitutes the essence of industry amalgamation and innovation simultaneously, integrated innovation formed the core power of promoting industry competence.

\section{Analysis on the inosculated development on the Telecom}

In the $4 \mathrm{G}$ times under the background of 'triple-networks convergence', the application of diverse removable media mostly reduced the position of traditional voice business. The compared focus during the enterprises is gradually becoming data value appreciation characterized by individuation of customer demands, customized profession, and service diversification. Here from, it will bring out restructure and elongation of Telecom industrial chain, which presented an appearance of Net and overlapping convergence. The restructured Telecom industrial chain as shown in Fig. 2 will remind the feature the modular. In the chain, the Carrier still be in the core position, which we called core modular, as well as that other value links in the chain won't be marginalized, which is to be in the important link of the work in co-operation chain, named value submodule, loaded with significant value creation function. The core modular and submodule provide kinds of value service to customer together, leading to cooperative and integration on the level of industry based on integrated innovation of common interface and rules.

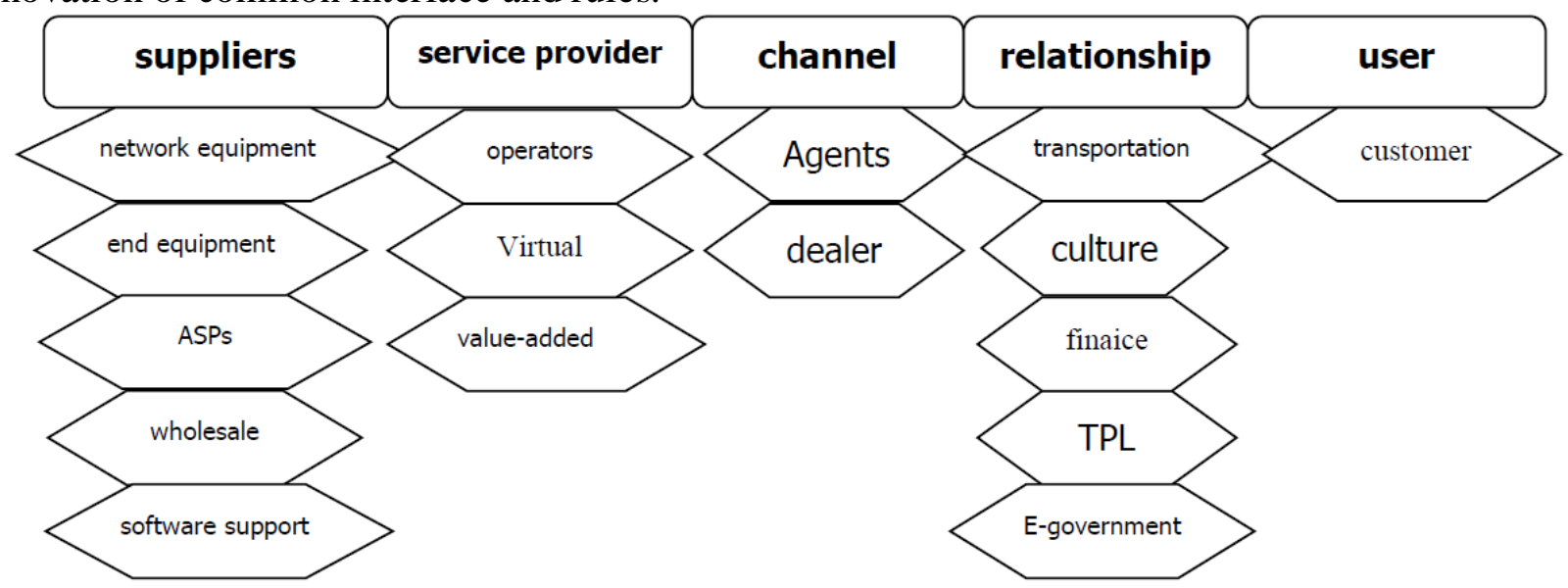

Figure 2 Constitution at Telecom industrial chain in the 4G Times based on modular theory

Constitution and analysis of modular of the Chinese Telecom industrial chain. As to as ideas of Baldwin \& Clark(2007), there are two class of rules in the system, which are optical rules such as tacit knowledge and invisible rules such as implicit knowledge. The former refers to the sharing and modifiable information and knoeledge such as conformation, interface, standard, and the latter refers to encapsulation rules of submodules. The feature of package can help submodules realizing integrated innovation and keeping core competence. The 'structure' of Chinese Telecom chain refers to the upstream part named collectively called submodule of suppliers to system include network device suppliers such as Huawei, Zte, terminal equipment suppliers, Internet Content Provider(ICP), Application Service Providers (ASP), E-business service, software supplier, traditional service supplier and so on. Also the mid-stream part named core modular of integrative company and the downstream part named modular of customer. The 'interface' of Chinese Telecom chain refers to management mechanisms of knowledge, value, benefit, which are altogether and connecting point of knowledge. The 'standard' of Chinese Telecom chain refers to network technology standard of $3 \mathrm{G}$ such as WCDMA, CDMA-2000, TD-SCDMA accepted by ITU. The invisible rules of Chinese Telecom chain refers to the governance mechanism based on implicit knowledge and proprietary 
technology, which are got by cooperative learning, sustaining innovation can help gain more dominant position in the chain.

Constitution and analysis of modular of the Chinese Telecom industrial chain. Integrated innovation of Chinese Telecom industry based on modular idea refers to the mechanism of knowledge division of the work, value integrated, profit shared, which include innovation foundation, innovation power, innovation platform, innovation path.

The integrated innovation foundation led by promotion of independence of submodule based on the implicit knowledge. Long time accumulation of implicit knowledge can help gaining the profit of division by sustain innovation focused on the simple field, on the other hand can provide real protection on intellectual property rights of submodule so as to improve innovation independence, such that Google as the CP supplier concentrates on sustained innovation of knowledge searching.

The integrated innovation power led by the competition and natural selection mechanism of mode of back to back during the submodules in the system. The common submodule and special submodule bring out a great choice for system integrator, and then form the zero game during submodules of suppler. Simultaneously, there is intense competition during the system integrator, such as the three-way struggle in the Chinese Telecom market, which strongly encourages the innovation power for each modular.

The integrated innovation platform is consisted of the feasible rules such as unitary structure, interface, and standard in the modular industrial chain. Parallel integrated submodules can realize rapid innovation in the form of 'plug in and play' through recombination, and achieve products diversification so as to respond on the individuation and customized demand of customers such as the realization of data value added business of mobile phone intercommunication and IPTV.

The integrated innovation path refers to the learning of competition and collaboration. There are three patterns. One pattern is that competition learning during the core modular can help design more advanced visible rules to put up their own value creation system. The second pattern is collaboration learning between core modular and suppler modular through the knowledge shared and creation to realize cooperative integrated innovation. The third pattern is the competition learning during the suppler modular. On the one hand they try to steady their implicit knowledge, on the other hand they seek excavating implicit of other submodule suppler.

\section{Conclusion}

The inosculated development and integrated innovation of Chinese Telecom industry from the view of modular is essentially restructure and upgrade of all value activity. Under the new industrial development pattern, mobile operators as the core modular should make the change of role from value realization or distribution to system value integration promptly. In addition, they should upgrade the business mode based on cooperation and all-win idea as well as the governance mechanism and benefit distribution pattern on the value-added foundation. Furthermore, they ought to positively search integrated kind of business innovation and technological advance based on the competition and cooperation learning with submodule in the system so as to realize the integrated value creation by conforming good quality submodule resource on a worldwide scale.

\section{Acknowledgement}

This research was one of the important principal components of object administered by professional education department in Shandong province, named by cultivation applicable and innovational works by school-enterprise cooperation. Many thanks for the human resource management department of State Grid Shandong Electric Power Research Institute.

\section{References}

[1] Masahi K. A., The essence of the new industrial structure in the modular times, M. Shanghai, Far-east Press, 2001, pp. 312-320. 
[2] Baldwin C. Design Rules, The power of modularity, M. Cambridge, MA: MIT Press, 2000, pp.256-260.

[3] Iansiti M., Jonathan W., Technology integration: turning great research into great products, J. Harvard Business Review, 12 (1997)45-49.

[4] Baldwin C., Managing in an age of modularity, J. Harvard Business Review, 10(1997)102-110.

[5] Gassan,R., Kumaraswmy,A., Changing competitive dynamics in Network Industries: An Exploration of Sun Microsystem's Open Systems Strategy, J. Strategic Management Journal, 9(2003)90-102. 